\title{
In Memory of V.F. Gantmakher
}

DOI: $10.1134 / \mathrm{S} 0021364015080123$

Vsevolod Feliksovich Gantmakher, Academician of the Russian Academy of Science and Honored Professor of the Moscow Institute of Physics and Technology (State University), passed away on March 5, 2015, after a long serious illness. His death is an irreparable loss for Russian science. He was an author of numerous scientific works widely known both in Russia and abroad. He wrote many popular reviews; several generations of scientists grew up on his books. His early works were awarded the Lenin Komsomol Prize; in middle age, he was awarded the Kapitza Gold Medal founded by the Russian Academy of Sciences.

From 1990 to 2011, Vsevolod Feliksovich was the editor-in-chief of the journal JETP Letters. These years were difficult for the journal. Gantmakher initi- ated the creation of the electronic version of the journal and the transformation of the communication with authors and referees, as well as the production of the layout, to the electronic form. In these years difficult for Russian science under the reduction of the amount and quality of research, Vsevolod Feliksovich managed not only to preserve the content of the journal but also to raise its authority in Russia and worldwide. The editorial board of the journal is sad for the death of V.F. Gantmakher and expresses deep condolences to his relatives and friends. 